\title{
PRINCIPIO DE IGUALDAD DE ARMAS EN LA LEY 906 DE 2004: PERCEPCIÓN DE LOS DEFENSORES PÚBLICOS DE CUNDINAMARCA
}

\author{
Eyner Adolfo Castro \\ Universidad Católica de Colombia
}

\section{Resumen}

Se elaboró un estudio sobre el principio de igualdad de armas en el sistema penal acusatorio colombiano, Ley 906/2004, que contrasta la parte formal del principio y la aplicación en las diferentes etapas del proceso penal, que probablemente causarían una violación al derecho fundamental de defensa de los investigados que no cuenten con los recursos económicos para desvirtuar la teoría de la Fiscalía. Para el efecto, se aplicaron instrumentos metodológicos, como encuestas y recopilación de información.

Palabras clave: investigación penal, sistema penal acusatorio, igualdad de armas, facultades de la defensa.

Autor: Técnico en Criminalística, 2004. Exfuncionario del CTI de la Fiscalía General de la Nación, 2007-2010. Funcionario del Grupo de Investigación Defensorial de la Defensoría del Pueblo, 2010 a la fecha. Docente en Criminalística. Universidad Católica de Colombia, Bogotá. Eynercastro79@ hotmail.com

Recibido: 7 de febrero de 2017; evaluado: 21 de marzo de 2017; aceptado: 2 de mayo de 2017. 


\title{
PRINCIPLE OF EQUALITY OF ARMS IN LAW 906 OF 2004: PERCEPTION OF PUBLIC DEFENDERS IN CUNDINAMARCA
}

\author{
Eyner Adolfo Castro \\ Universidad Católica de Colombia
}

\begin{abstract}
A study on the principle of equality of arms in the Colombian accusatory penal system under law 906/2004 was developed, contrasting the formal part of the principle and its implementation in the different stages of criminal proceedings, which would likely cause an infringement of the fundamental right to an attorney for defendants who do not have the economic resources to hire representation. To that end, we implemented methodological surveys and data collection instruments.
\end{abstract}

Keywords: criminal investigation, accusatory criminal system, equality of arms, powers of the defense.

About the author: Forensic science technician, 2004. Former member of the Technical Investigation Team (CTI) of the Office of the Attorney General of Colombia, 2007-2010. Member of the Defense Investigation Team of the Office of the People's Advocate, 2010 to date. Forensic Science professor at Universidad Católica de Colombia, Bogotá. Eynercastro79@hotmail.com

Received: February 7, 2017; evaluated: March 21, 2017; accepted: May 2, 2017. 


\section{Introducción}

Con la entrada en vigencia de la Ley 906 de 2004, también conocida como Sistema Penal Acusatorio, se pretendía cambiar la forma de aplicar el derecho penal. Para esto se valió del principio de igualdad de armas, el cual sitúa en un plano de equivalencia a las partes: la Fiscalía y la defensa. Cada una tiene la posibilidad de acceder a todos los recursos disponibles, según su objetivo particular: la Fiscalía, para acusar a un ciudadano, según lo contemplado en el art. 250 de la Constitución Política de 1991, y la defensa, para proteger y asesorar al acusado, cuente o no con medios económicos para ello, según el art. 282, núm. 4, de la Constitución de 1991¹.

La aplicación del principio de igualdad de armas del que se habla en el articulado de la Ley 906 de 2004 se quedó en la parte formal, y su aplicación material se ha visto relegada, ya que la Fiscalía es la que cuenta con gran cantidad de recursos económicos, técnicos, científicos y humanos para investigar. Por tal motivo, tratar de igualar este poder es sinónimo de quebrantamiento de igualdad de medios; lo que se suma, además, a la poca aplicación de este principio por parte de los operadores e intervinientes del sistema. Por ello, es importante conocer las herramientas que brinda el principio en cita, para lograr que se hagan efectivos los derechos que tiene la defensa, con el fin de que la contienda sea más equitativa y, de esta forma, las tesis que se presenten ante el juez de la causa tengan el mismo peso, para lograr una justicia más objetiva².

Con el fin de establecer si esta situación se presenta en la actualidad, se toma como marco de estudio el Departamento de Cundinamarca, teniendo en cuenta que dentro del funcionamiento del Sistema Nacional de Defensoría Pública se cubren los 116 municipios, pero se exceptúa a Bogotá, por ser una regional independiente; por ende, el trabajo de defensa se ejerce en cada circuito judicial, lo cual genera que los defensores públicos realicen desplazamientos hasta dichas zonas para prestar su servicio; también los investigadores y peritos que se encuentran en la sede central (Bogotá), dentro de las restricciones de recursos logísticos y el número limitado de profesionales en derecho que asumen un alto volumen de casos $^{3}$.

Rodrigo Uprimny, et al., Reflexiones sobre el nuevo sistema procesal penal. Los grandes desafios del juez penal colombiano (Bogotá: Imprenta Nacional, 2006).

2 Manuel Fernando Moya Vargas, Cuatro aspectos polémicos de la ley 906 de 2004 (Bogotá: Imprenta Nacional de Colombia, 2006).

3 Defensoría del Pueblo, Manual del investigador desde la perspectiva de la defensa (Bogotá, 2008). 
Para estar en contexto con el estudio, se resalta que el departamento de Cundinamarca cuenta, en sus 116 municipios, con una proyección de 2'721.368 habitantes para el 2016, de acuerdo con datos del Departamento Administrativo Nacional de Estadística (DANE) ${ }^{4}$. El departamento tiene asignados 104 defensores públicos para cubrir la demanda en el área penal ${ }^{5}$, esto quiere decir que la proporción es de 0,89 defensores públicos por municipio.

Por esto, la pregunta que se plantea en esta investigación es: ¿cómo se aplica el principio de igualdad de armas de la Ley 906 de 2004 en el departamento de Cundinamarca, según la percepción de los defensores públicos?

La hipótesis que se pretende demostrar es que el principio de igualdad de armas no se aplica de forma generalizada en los circuitos judiciales penales de Cundinamarca, y que existen elementos y situaciones que vulneran el ejercicio de la defensa, en los que la persona procesada es la más afectada.

Como objetivo principal, se busca establecer cuáles son los factores que afectan el principio de igualdad de armas en el departamento cundinamarqués, desde la perspectiva de los defensores públicos. De igual forma, se establecerá si los fiscales y jueces aplican el principio, y, de no hacerlo, se determinará con qué actuaciones vulneran la igualdad de armas.

Este trabajo de campo es de tipo descriptivo. Se utilizaron encuestas para la recolección de información y se observaron las características propias de la región; es decir: número de defensores, cantidad de municipios que cubre, grupo de investigadores y peritos.

\section{Antecedentes del principio de igualdad de armas}

En Colombia, al inicio del segundo milenio regía la Ley 600 de 2000, un sistema penal inquisitivo, en el cual la Fiscalía General de la Nación (FGN) era la encargada de investigar lo favorable y desfavorable; así, podía terminar indagaciones, acusar y afectar o restringir derechos. En contraposición, la defensa solo podía pedir copia

\footnotetext{
Departamento Nacional de Estadística de Colombia, "Demografía y población. Proyecciones de población”, 2016. http://www.dane.gov.co/index.php/estadisticas-por-tema/demografia-y-poblacion/proyecciones-de-poblacion

5 Congreso de la República de Colombia, Ley 906 de 2004, por la cual se expide el Código de Procedimiento Penal (Corregida de conformidad con el Decreto 2770 de 2004) (Bogotá: Diario Oficial 45.658, 31 de agosto de 2004).
} 
de lo actuado si el imputado rendía versión libre, con lo cual quedaba vinculado al proceso $0^{6}$ o allegar pruebas o controvertir las existentes, mediante escritos adheridos al voluminoso expediente $e^{7}$, para que el juez evaluara y diera una sentencia con las pruebas arrimadas al sumario 8 .

Con la entrada en vigencia de la Ley 906 de 2004 se pretendió dar un giro al sistema, ya que: "Como desarrollo del derecho de defensa, el imputado o su defensor pueden no solo contrainterrogar a los testigos, sino aducir otras pruebas que mengüen el valor de las obrantes y cuestionar la veracidad y legalidad de los medios probatorios o señalar su real aporte en punto del objeto de investigación".

Es indudable que la FGN, como encargada de investigar y acusar penalmente, es un ente inmenso frente a lo que un abogado puede hacer para lograr la defensa de su prohijado. El problema empieza cuando el ciudadano, además de llevar la carga de afrontar un proceso penal, tiene que buscar un representante que lo asesore técnica y materialmente, y adicionalmente, llevar medios de convicción, pero todo de su peculio ${ }^{10}$.

Ante este panorama, se observa que: "La defensa, que garantiza el cumplimiento de las reglas del debido proceso, se encuentre en un estado de desventaja frente al acceso a los medios técnicos, humanos y jurídicos de investigación, lo cual obstaculiza notablemente el ejercicio real y material de derecho a la defensa, núcleo esencial del debido proceso"11.

Esta obligación se puede afrontar cuando se cuenta con recursos económicos suficientes para estar a la altura del contrincante, pero cuando no se tiene dinero, el derecho fundamental de la igualdad se desvanece y la persona no tendría más remedio que allanarse para obtener algún "descuento" en la pena, o ver cómo es

6 Congreso de la República, Ley 600 de 2000, por la cual se expide el Código de Procedimiento Penal (Bogotá: Diario Oficial 44.097 del 24 de julio de 2000), art. 325.

\section{Ibid., art. 255.}

8 Carlos Andrés Bernal, Reflexiones de derecho penal y procesal penal (Bogotá: Defensoría del Pueblo, Imprenta Nacional, 2013).

9 Alfonso Daza, "El principio de igualdad de armas en el sistema procesal penal Colombiano a partir del Acto Legislativo 03 de 2002", Revista Principia IURIS. Centro de investigaciones Socio-Jurídicas USTA TUNJA, 12, (2009). http://revistas.ustatunja.edu.co/index.php/piuris/article/view/396

10 Alejandro Sánchez, "Modelo procesal penal colombiano ¿es adversarial?" Ambito Jurídico, (2016). https://www.ambitojuridico.com/BancoConocimiento/Penal/modelo-procesal-penal-colombiano-es-adversarial?CodSeccion=1

11 Iván Alfredo Otero, "Ineficacia del ejercicio del derecho a la defensa técnica en el proceso penal a la luz del principio de igualdad de armas", En Temas de defensa penal, Tomo I (Bogotá: Imprenta Nacional de Colombia, 2014), 178 . 
condenado, a sabiendas de que se podrían hacer muchas cosas que fueran más favorables a su caso; por ello: "La facultad legal que otorga la actual legislación acusatoria procesal penal a la defensa para que pueda adelantar su propia investigación está encaminada a llevarle al juez, quien es la persona que va a decidir sobre el asunto de fondo, una perspectiva de verdad diferente de la que construya su opositor dialéctico, como es la fiscalía"12.

\section{Principios de la Ley 906 de 2004}

Como lo plantean Jiménez y Valdés ${ }^{13}$, en el título preliminar de la Ley 906 de 2004 se encuentran los principios rectores y las garantías procesales, los cuales pretenden dar luces en materia de interpretación y fines que persigue esta ley. Por esto, es pertinente hacer su estudio, y para el caso se relacionan algunos de ellos, que son afines con el desarrollo del principio de igualdad de armas.

\subsection{El principio de igualdad}

Es obligación de los servidores judiciales hacer efectiva la igualdad de los intervinientes en el desarrollo de la actuación procesal, y proteger, especialmente, a aquellas personas que por su condición económica, física o mental se encuentren en circunstancias de debilidad manifiesta ${ }^{14}$.

En el texto constitucional colombiano se encuentra que "Todas las personas nacen libres e iguales ante la ley, recibirán la misma protección y trato de las autoridades y gozarán de los mismos derechos, libertades y oportunidades sin ninguna discriminación"15.

El eje del análisis que realiza la Corte Constitucional en la Sentencia C-799 de 2005 es que "el derecho a la igualdad debe ser interpretado como una igualdad entre iguales y una desigualdad entre desiguales"16. Para que se aplique la igualdad de

12 Carlos Felipe Sánchez, El desarrollo de nuestro sistema penal de corte acusatorio y la actuación de las partes e intervinientes frente a disposiciones constitucionales. Análisis y aportes para su consolidación. Reflexiones de derecho penal y procesal penal (Bogotá: Imprenta Nacional, 2013), 441.

13 Fernando Jiménez Montes y Carlos Eduardo Valdés Moreno, Colección sistema penal acusatorio, Tomo I (Bogotá: Universidad Católica de Colombia, 2009).

14 Congreso, Ley 906 de 2004, art. 4.

15 Constitución Politica de Colombia, art. 13. 1991. http://www.corteconstitucional.gov.co/inicio/Constitucion\%20 politica\%20de\%20Colombia\%20-\%202015.pdf

16 Corte Constitucional de Colombia, Sala Plena. Sentencia C-799/05, Cosa Juzgada Constitucional-Configuración. Obligaciones de los servidores judiciales y derecho a la igualdad-Protección de personas que se encuentren en 
un ciudadano acusado frente a la FGN tendría que ser igual, cosa que, en la práctica, ninguna persona cumple; por tal motivo, se podría decir que la condición de desigualdad sería evidente, por ello se debe aplicar desigualdad entre desiguales.

De igual forma, encontramos que "una vez adquirida la condición de imputado, este tendrá derecho, en plena igualdad respecto del órgano de persecución penal [... ]"17, entendiendo que la defensa puede realizar actividades y sustentar su teoría del caso como lo hace la Fiscalía ${ }^{18}$.

\subsection{Principio de imparcialidad}

Se encuentra que "En ejercicio de las funciones de control de garantías, preclusión y juzgamiento, los jueces se orientarán por el imperativo de establecer con objetividad la verdad y la justicia"19, con lo cual se pretende establecer que quien toma las decisiones en el caso que las partes presentan sea ajena a cualquier tipo de presión, libre de prejuicios, y que escuche los argumentos, y con estos dé su veredicto, sin estar a favor de uno de los extremos del debate penal. Por esto: "En desarrollo del principio de imparcialidad que debe imperar en las actuaciones judiciales, la legislación procesal ha previsto una serie de causales de orden objetivo y subjetivo en cuya concurrencia el juez debe declararse impedido, o los sujetos procesales pueden recusarlo, para decidir, garantizando a las partes, terceros y demás intervinientes la transparencia, sindéresis y ecuanimidad propias de la administración de justicia"20.

Para garantizar este principio, encontramos los impedimentos y recusaciones ${ }^{21}$, los cuales no solo le permiten al juez la posibilidad de manifestarse en caso de que no pueda ser imparcial por alguna de las causales, sino que también les da la posibilidad a las partes de recusarlo, para buscar así un juicio ecuánime.

circunstancias de debilidad manifiesta. Referencia: expediente D-5464, MP Jaime Araujo Rentería (Bogotá: 2 de agosto de 2005), art. 13.

17 Congreso, Ley 906 de 2004, art. 8.

18 C. A. Reyes Medina, Técnicas del proceso oral en el sistema penal acusatorio colombiano: Manual General para operadores jurídicos $2^{\mathrm{a}}$ ed. (Bogotá: USAID, 2009).

19 Congreso, Ley 906 de 2004, art. 5.

20 Corte Suprema de Justicia, Sala de Casación Penal, Sentencia SP12031-2015, MP Luis Guillermo Salazar Otero (Bogotá: 9 de septiembre de 2015).

21 Congreso, Ley 906 de 2004, arts. 56-65. 


\subsection{Principio de legalidad}

La ley penal colombiana establece que "Nadie podrá ser investigado ni juzgado sino conforme a la ley procesal vigente al momento de los hechos, con observancia de las formas propias de cada juicio"22.

Este principio encuentra su correspondencia en el texto constitucional: "nadie podrá ser juzgado sino conforme a leyes preexistentes al acto que se le imputa"23. Igualmente se encuentra en la ley penal colombiana que se observarán "las formas propias de cada juicio", y se sujetará a las partes a lo establecido en todo el contenido normativo, tanto en oportunidades, como en requisitos, términos y garantías.

El principio de legalidad referido al proceso penal no se limita hoy en día a la preexistencia formal de ritos y funcionarios competentes, sino que se extiende a nociones de naturaleza eminentemente procesal, pero de contenido sustancial, y, además, a cuestiones estrictamente sustanciales, que se han visto alternadas, complementadas y en algunos casos subordinadas por factores de carácter procesal2 ${ }^{24}$.

\subsection{Principio de defensa}

La Constitución Política de Colombia de 1991 establece, en el artículo 29, entre otros aspectos, que todas las personas se presumen inocentes hasta que sean declaradas judicialmente culpables, y en caso de ser sindicado, tiene derecho a la defensa y a la asistencia de un abogado de confianza, o suministrado por el Estado durante todo el proceso. Bajo este entendido, según la Ley 906 de 2004, art. 8: "[...] una vez adquirida la condición de imputado, este tendrá derecho, en plena igualdad respecto del órgano de persecución penal [...]". Se puede decir que cada persona que enfrenta la acusación de la FGN, lo hace en condiciones de inocente y puede realizar actividades para mantener dicha presunción, contando con la ilustración y asesoría de un profesional del derecho, para que el binomio (acusado-defensor) asuma la estrategia más favorable en el caso particular ${ }^{25}$.

Congreso, Ley 906 de 2004, art. 6.

Constitución Política, art. 29.

24 Gerardo Barbosa, "Principio de legalidad y proceso penal", Revista Derecho Penal y Criminología Universidad Externado de Colombia, vol. 26, n. ${ }^{\circ}$ 78, (2005): 116.

25 Yolanda Chiappe, El derecho de defensa frente a la formalización de la Investigación. Reflexiones de derecho penal y procesal penal (Bogotá: Imprenta Nacional, 2013). 
Como se observa, no se encuentra en el articulado de la Ley 906 de 2004, de manera explícita, el "principio de igualdad de armas", pero se puede decir que lo establecido en el artículo 8, sumado a los principios citados con el correspondiente desarrollo de las altas cortes, deja claro que este principio es una de las columnas más importantes del llamado sistema penal acusatorio colombiano, como se analizará a continuación.

\section{Principio de igualdad de armas. Una realidad formal desde la ley}

El esquema del sistema penal acusatorio se estructura en dos partes. Por un lado, la Fiscalía General de la Nación como representante del Estado (como lo plantea Solórzano 26 "en el caso colombiano no se puede decir que la Fiscalía sea el Representante del gobierno, porque sigue siendo parte del poder judicial y tiene autonomía y total independencia"), la cual es la encargada de la persecución penal. Por otro lado, el acusado, acompañado de su abogado (de confianza o suministrado por la defensoría pública), quienes forman el equipo de la defensa. Y como encargado de dirimir el litigio está el juez ${ }^{27}$.

Cada parte cumple su rol. La Fiscalía desvirtúa la presunción de inocencia para pedir condena, y la defensa mantiene dicha presunción, al plantear la duda razonable o realizar una negociación cuando los elementos descubiertos sean suficientes para pensar que el fiscal vencerá en juicio, por lo cual se debe optar por alguna de las formas alternativas de terminación del proceso.

Al revisar la exposición de motivos del proyecto para debatir lo que hoy se conoce como Ley 906 de 2004, en el primer informe de ponencia se encuentra lo que en su momento se consideró un avance significativo en aspectos como los siguientes:

El proyecto de ley sometido a nuestro estudio, 'por la cual se expide el Código de Procedimiento Penal', consta de un título preliminar referido a los principios rectores y garantías procesales tradicionalmente consagrados en las codificaciones afines, con el importante agregado de normas rectoras de gran contenido y desarrollo para un sistema acusatorio, como son los derechos a

26 Carlos Roberto Solórzano, Sistema acusatorio y técnicas del juicio oral, $4^{\mathrm{a}}$ ed. (Bogotá: Ediciones Nueva Jurídica, 2012), 66.

27 Carlos Arias Duque, La nacional de capacitación: sistema nacional de Defensoría Pública (Bogotá: Defensoría del Pueblo/USAID, 2006). 
la intimidad y a la defensa; los derechos de las víctimas y los principios de contradicción, inmediación, concentración y publicidad. ${ }^{28}$

En el mismo informe se encuentra el origen de la audiencia de formulación de imputación: "Formulación de la imputación. Esta figura, novedosa aun en sistemas acusatorios, consiste en la comunicación que la Fiscalía General de la Nación hace a una persona de su calidad de imputado. El proyecto se ocupa de regular específicamente las situaciones que la propician, las formalidades que debe satisfacer, la activación de la defensa a partir de entonces, entre otros aspectos" ${ }^{29}$.

Con el cambio de sistema mixto, a uno con tendencia acusatoria, se pretendía establecer roles claros a las partes, con la dotación de herramientas y medios para que cada quien ejerciera su labor, y la aplicación de nuevos principios que garantizaran una recta y pronta administración de justicia; así, con la incorporación de la formulación de acusación se pretendía hacer más transparente y garantista el proceso para ejercer la debida defensa desde los orígenes del proceso ${ }^{30}$.

Es decir, en un sistema de partes, se estaría hablando de que la Fiscalía y la defensa presentarían los elementos, testigos y peritos que consideraran pertinentes para demostrar su teoría, con las mismas herramientas y oportunidades respecto a la contraparte, y practicarían estas pruebas frente al juez de conocimiento, así se ejercería el contradictorio para obtener una verdad procesal, que será fundamento de la sentencia del director del proceso penal ${ }^{31}$.

En Colombia, con la Ley 906 de 2004, la defensa inicia cuando el investigado se entera de que se está adelantado una investigación en su contra, o cuando se convoca a la audiencia de imputación de cargos, o cuando es capturado en situación de flagrancia y es llevado a las audiencias concentradas.

El imputado, de acuerdo con la Ley penal, art. 8, parágrafo e, tiene derecho a "Ser oído, asistido y representado por un abogado de confianza o nombrado por el Estado", con lo cual se empieza a "garantizar" el derecho de defensa, técnica y

28 Congreso de Colombia, Cámara de Representantes, "Informe de ponencia para primer debate al proyecto de Ley 01 de 2003" http://www.imprenta.gov.co/gacetap/gaceta. mostrar_documento?p_tipo=22\&p_numero=01\&p_consec $=7350$

29 Congreso de Colombia, Cámara de Representantes, "Proyecto de Ley 01 de 2003", s. p.

30 Daza, "El principio de igualdad de armas en el sistema procesal penal".

31 Whanda Fernández, "El mito de la igualdad de armas", Ámbito Jurídico https://www.ambitojuridico.com/ BancoConocimiento/Educacion-y-Cultura/noti-143010-05-el-mito-de-la-igualdad-de-armas 
material, y la oportunidad de recolectar información por medio de un investigador: elementos materiales de prueba y evidencia física, ubicar y entrevistar testigos, contratar peritos; todo lo anterior, para poder ser presentado en la audiencia de juicio oral, y esto a costas del procesado.

Si una persona no cuenta con recursos económicos para garantizarse una defensa de confianza, podrá ser asistido por un abogado que suministra el Estado mediante el Sistema Nacional de Defensoría Pública, aquellos que el común de las personas llaman "abogados de oficio", pero que se denominan defensores públicos; estos abogados, con capacitación y experiencia, son contratistas de la Defensoría del Pueblo y prestan sus servicios para proveer la defensa técnica y material, sin ningún costo para el usuario.

Los defensores públicos, a su vez, cuentan con el apoyo del Grupo de Investigación Defensorial (GID), un cuerpo de investigadores, técnicos y peritos que realizan la investigación para fortalecer la teoría defensiva y llegar en igualdad de medios a una audiencia de juicio oral.

Para el 2016, la Defensoría del Pueblo contaba con aproximadamente 4.200 abogados contratistas, a escala nacional, con los cuales se cubren varios programas (penal, civil, familia, representación de víctimas, entre otros).

En el departamento de Cundinamarca están asignados 104 defensores públicos en el programa del área penal o Ley 906 de 2004, y estos a su vez se apoyan en el Grupo de Investigación Defensorial, que cuenta con 13 funcionarios, quienes cubren todo el departamento y tienen la función de realizar la investigación y obtener elementos útiles para la defensa; esto, con el fin de equiparar lo hecho por los investigadores de la FGN, que tienen funciones de policía judicial, adscritos tanto a la Sijin (Policía Nacional) como al Cuerpo Técnico de Investigación (CTI).

Si se observa el sistema penal acusatorio desde un punto de vista financiero, para el caso de la Fiscalía General de la Nación, la tarea de acusar se realiza con los recursos asignados para su funcionamiento, que para el 2016 ascendieron a \$2.895.676’929.040.oo 32 y su labor principal es ejercer la acción penal, según se

32 Presidencia de la República, Decreto 2550 de 2015, por el cual se liquida el Presupuesto General de la Nación para la vigencia fiscal de 2016, se detallan las apropiaciones y se clasifican y definen los gastos (Bogotá, 30 de diciembre de 2015), art. 3, secc. 2502. http://inm.gov.co/images/Normatividad/Decretos/Decreto_\%20 2550_2015.pdf 
establece en el artículo 250 de la Constitución Política de Colombia; así, es un ente que cuenta con funcionarios, laboratorios, peritos e investigadores con funciones de policía judicial.

Por otra parte, la Defensoría del Pueblo tuvo asignados para su funcionamiento en el 2016, \$417.599'260.000.00 33, para la promoción, fomento y protección de los derechos humanos, así como para orientar y proveer el acceso a la administración de justicia. Uno de estos frentes de trabajo es el Sistema Nacional de Defensoría Pública, el cual, entre muchas otras actividades, asume la defensa y representación judicial de quienes lo requieren ${ }^{34}$. Esto es una muestra de desigualdad, pues solo tiene asignado el 14,42\% del presupuesto respecto al ente acusador.

Ahora bien, teniendo en cuenta que un punto de referencia sobre el sistema penal acusatorio que se tiene en el país es el sistema estadounidense, se destacan algunas de sus características respecto a la actividad de la defensa: "El sistema legal de los EE. UU. se basa en el proceso acusatorio y los abogados son una parte esencial del proceso, responsables por presentar las pruebas y los argumentos legales de sus clientes ante un tribunal. Dependiendo en la presentación del abogado, el juez de primera instancia o el jurado determina los hechos y aplican la ley para llegar a una decisión antes de emitir un fallo"35.

Esto quiere decir que sin elementos de convicción o argumentos, la tesis del abogado no prosperará y la decisión del juez (o jurado) será adversa a sus intereses; lo cual permite observar la importancia de la actividad proactiva del jurista en el caso particular.

En la Ley 906 de 2004 existen dos audiencias, en las que cada parte descubre a la otra el material con el que cuenta para sustentar su posición. En la audiencia de acusación, la fiscalía enuncia y posteriormente entrega a la defensa los elementos, para dar paso a la actividad investigativa de la defensa, con el fin de que esta refute o desvirtúe dichos elementos de convicción, para entregarlos en la audiencia preparatoria. Actividad similar se encuentra en el sistema estadounidense que se toma como referencia:

Presidencia, Decreto 2550 de 2015.

34 Congreso de la República de Colombia, Ley 941 de 2005, por la cual se organiza el Sistema Nacional de Defensoría Pública (Bogotá: Diario Oficial 45.790 del 14 de enero de 2004).

35 Federal Judicial Center, "El sistema judicial de los EEUU". (2007). http://www2.fjc.gov/sites/default/ files/2014/US_Legal_Sys_Spanish_2007_Jul.pdf 
El fiscal y la defensa intercambiarán información. Esto se llama "revelación". Es posible que los acusados no puedan ver toda la información intercambiada, pero sus abogados en general no tienen esta limitación. Esto se debe a que los abogados están obligados por ley a proteger la identidad de los testigos mientras están preparando la defensa, para que los testigos no corran peligro. Por eso es tan importante que una persona acusada de haber cometido un delito menor o mayor sea representada por un abogado. ${ }^{36}$

Otro elemento importante es la forma de terminación del proceso, el cual no es siempre por pronunciamiento del juez después de efectuar un juicio oral. En el sistema estadounidense se encuentra una fortaleza en el tema de negociación entre las partes, el cual es bastante común, porque: "Si bien el proceso mediante jurado sigue siendo un elemento fundamental del sistema judicial estadounidense, los jurados deciden menos de un cinco por ciento de las disputas planteadas en la mayoría de las jurisdicciones de Estados Unidos. Algunos casos son vistos por un juez sin la presencia de un jurado, pero la vasta mayoría de los casos son resueltos por negociación entre las partes" ${ }^{\prime 37}$.

Un elemento importante en el sistema estadounidense es el arreglo entre los interesados en el proceso; esta situación es la más frecuente, lo que genera un procedimiento judicial más efectivo y genera gran confianza en el sistema.

\subsection{El principio de igualdad de armas desde la jurisprudencia colombiana}

Una vez entró en vigencia la Ley 906 de 2004, las altas cortes se pronunciaron respecto a la igualdad de armas, para dar claridad a este principio; aunque no se encuentra en el articulado de manera explícita, sino que más bien se deriva su existencia de la suma de los principios. Como muestra de esto encontramos que la Corte Constitucional, en la Sentencia T-432 ${ }^{38}$, precisó: "El principio de la igualdad se traduce en el derecho a que no se instauren excepciones o privilegios que exceptúen a unos individuos de lo que se concede a otros en idénticas circunstancias, de

36 Judicial Branch Home, Cortes de California, "Cómo funcionan los casos penales" http://www.courts. ca.gov/1069.htm

37 United States of America Embassy. "Sistema judicial de E.U.: viejas tradiciones, nuevas direcciones". (2003). http://iipdigital.usembassy.gov/st/spanish/texttrans/2003/06/20030617113215neerge0.9618189.html \#ixzz4M4UqOKg2

38 Corte Constitucional de Colombia. Sentencia No. T-432 MP Simón Rodríguez Rodríguez (Bogotá: 25 de junio de 1992). 
donde se sigue necesariamente, que la real y efectiva igualdad consiste en aplicar la ley en cada uno de los acaecimientos según las diferencias constitutivas de ellos" ${ }^{\prime 39}$.

Este es uno de los conceptos más claros respecto a lo que significa la igualdad de armas dentro del ámbito penal en Colombia, el cual sentó las bases para un desarrollo jurisprudencial, en el que el concepto se refuerza y se amplía. Por ello, se resaltan, entre otros, el siguiente pronunciamiento: "El principio de igualdad de armas o igualdad de medios, supone entonces que la carga probatoria del acusador es proporcional a sus medios y que las reglas de ejercicio del principio contradictorio en virtud de esa carga, buscan equiparar la participación en el proceso penal, tanto optimizando lo más posible las garantías de la defensa, como incrementando la exigencia del cumplimiento de la labor probatoria del acusador" ${ }^{\prime \prime 0}$.

Lo anterior se puede entender como la aplicación de la desigualdad entre partes desiguales, al aumentar la exigencia a quien tiene los medios e incrementar las garantías a la defensa, para procurar así una igualdad de armas en el proceso penal.

Además, conforme con la doctrina internacional sobre el tema, el derecho a contrainterrogar a los testigos se encuentra íntimamente ligado con el mencionado principio de "igualdad de armas", y por él se entiende que la defensa debe poder contrainterrogar al testigo en igualdad de condiciones que la agencia estatal encargada de sustentar la acusación penal. Así lo ha entendido, en numerosas sentencias, la Corte Europea de Derechos Humanos, cuya doctrina ha sido explícitamente acogida por la Corte Interamericana, y es por ende relevante para interpretar el contenido de los derechos constitucionales, tal y como esta Corte Constitucional lo ha señalado en numerosas ocasiones ${ }^{41}$.

Con este derecho se da paso a una defensa activa que busca desvirtuar la tesis de la FGN, al dar al juez la posibilidad de escuchar toda la versión de los hechos y llegar más allá, para observar no solo lo relevante, sino los detalles, la calidad y la personalidad del testigo, y salir fortalecido o desvirtuado después del examen cruzado de las partes.

39 Ibid., art. 2.1.

40 Corte Constitucional de Colombia, Sentencia T-1110 del 28 de octubre de 2005, MP Humberto Antonio Sierra Porto.

41 Corte Constitucional de Colombia, Sentencia SU 1300, MP Marco Gerardo Monroy Cabra (Bogotá: 6 de diciembre de 2001). 
En relación con el derecho a la defensa técnica, conocido en el modelo de tendencia acusatoria como el principio de "igualdad de armas", la jurisprudencia constitucional ha sido enfática en sostener que este hace parte del núcleo esencial del derecho a la defensa y al debido proceso, y su garantía plena es particularmente relevante si se considera que de su ejercicio se deriva la garantía de otros derechos, como el de igualdad de oportunidades e instrumentos procesales ${ }^{42}$.

La importancia del principio en cita toma capital importancia al ponerlo al nivel del derecho de defensa y al debido proceso, y su violación podría tenerse como fuente de recursos judiciales, ampliamente desarrollados por la jurisprudencia.

De igual forma, en un proceso dispositivo no es posible que existan decisiones implícitas, pues en el evento en que el funcionario judicial responda parcialmente a las solicitudes probatorias de las partes, debe aceptarse que estará vulnerando de inmediato uno de los pilares del sistema adversarial: la igualdad de trato jurídico entre los sujetos procesales, más conocida como "igualdad de armas en el proceso penal". Ello, toda vez que en una fase siguiente, las falencias que alberga su proveído se harán evidentes, ya sea porque ante la imposibilidad de ingresar o practicar un medio probatorio la parte afectada así lo alegue o, como en el caso presente, porque el juez, en aras de sanear o enmendar su error, se verá impelido a adoptar determinaciones que privilegian o dan supremacía a una de las partes, en tanto fallará conforme a sus propios prejuicios ${ }^{43}$.

Es claro, así, para las altas cortes, que el respeto por el principio de igualdad de armas, o de medios, es el eje del sistema penal de tendencia acusatoria que rige en Colombia, y su desconocimiento no solo vulnera el ejercicio de la defensa, sino que viola el debido proceso, el derecho de defensa y el derecho fundamental de igualdad.

\section{2 ¿Igualdad material?}

Como se observó anteriormente, alguno de los factores que podría generar la desigualdad de las partes es el económico. En este caso en particular, se manifiesta en la mayor cantidad de recursos asignados a la FGN, frente a los de la Defensoría del Pueblo, como número de personal dedicado al área penal, laboratorios y demás

42 Corte Constitucional de Colombia, Sentencia C-127, MP María Victoria Calle Correa (Bogotá: 2 de marzo de 2011).

43 Corte Suprema de Justicia, Sentencia AP5911, MP Fernando Alberto Castro Caballero (Bogotá: 8 de octubre de 2015). 
medios para realizar la misión institucional; pero existen otras formas de quebrar el principio de igualdad de armas, por ejemplo, el tiempo que tiene cada parte para realizar su labor.

Cuando el ente acusador empieza a desplegar su actividad de indagación cuenta con unos términos bastante amplios, contemplados en la Ley 906 de 2004, art. 175, que establece:

La Fiscalía tendrá un término máximo de dos años contados a partir de la recepción de la noticia criminis para formular imputación u ordenar motivadamente el archivo de la indagación. Este término máximo será de tres años cuando se presente concurso de delitos, o cuando sean tres o más los imputados. Cuando se trate de investigaciones por delitos que sean de competencia de los jueces penales del circuito especializado el término máximo será de cinco años. Parágrafo. En los procesos por delitos de competencia de los jueces penales del circuito especializados, por delitos contra la Administración Pública y por delitos contra el patrimonio económico que recaigan sobre bienes del Estado respecto de los cuales proceda la detención preventiva, los anteriores términos se duplicarán cuando sean tres (3) o más los imputados o los delitos objeto de investigación. ${ }^{44}$

Esto quiere decir que el término para desarrollar el programa metodológico, recopilar información, realizar entrevistas, someter en cadena de custodia los elementos materiales de prueba y evidencia física, y de ser necesario enviarlos a los laboratorios y pedir análisis a los peritos requeridos, para así estructurar la teoría del caso, oscila entre los 2 y los 10 años.

Ahora, en el caso de la defensa, generalmente se entera del proceso cuando se lleva a cabo la audiencia de imputación, pero no puede tener acceso a los elementos en su contra; así, realiza una investigación "presumiendo" lo que tiene la carpeta del caso; solo en la audiencia de acusación la Fiscalía descubre su "material probatorio", con el cual pretende vencer la presunción de inocencia, y en ese momento el binomio acusado-defensor conoce lo que tiene la contraparte, para, con base en ello, trazar la estrategia defensiva definitiva; pero cuentan con 45 días para llegar a la audiencia preparatoria y descubrir los elementos que pretenden hacer valer en juicio oral. Esta es una muestra clara de desigualdad en contra del acusado.

44 Congreso, Ley 906 de 2004, art. 175. 
En el hipotético caso de que la FGN recopile todo lo necesario para estructurar su caso en un periodo de dos años (720 días), junto con sus funcionarios de Policía Judicial, la defensa debe llegar a buscar testigos, elementos, información, después de dos años de ocurrido el hecho, y realizar todos los análisis con funcionarios que no tienen funciones de policía judicial, pero que cuentan con experiencia y profesionalismo, todo en menos de 45 días, para llegar a la audiencia preparatoria; en esta se pedirá que se tengan en cuenta los elementos de convicción encontrados y estar en igualdad de condiciones ante el ente acusador. Esta hipótesis se complica cuando la Fiscalía ha tomado más tiempo, 4, 6 u 8 años (entre 1.440 y 2.880 días), pues encontrar testigos o elementos después de todo ese lapso para realizar la defensa en mes y medio se convierte en una misión poco fructífera, lo que evidencia una clara vulneración al principio de igualdad y de defensa.

\subsection{Igualdad de medios entre las partes}

Recalcando parte del contenido del artículo 8 de la Ley 906 de 2004, el cual establece que el imputado actuará "en plena igualdad respecto del órgano de persecución penal", se entra a analizar si este principio se cumple y cuál podría ser su interpretación, acorde con lo que sucede en el desarrollo de las audiencias.

En palabras de Manuel Fernando Moya, durante el desarrollo de la barra académica, en la Escuela de la Defensoría del Pueblo ${ }^{45}$, la igualdad de armas no es cuestión de fuerza, sino de unas reglas compartidas, que vincula a las partes, en desconsideración del puesto que cada uno ocupa; por ello, se podría decir que no se trata de fortaleza institucional, sino de contar con las mismas condiciones para estructurar las pruebas.

Entonces, desde este punto de vista, el juez empieza a tener un papel importante, al ser el garante no solo del proceso, sino de las reglas constitucionales y legales; además de ser el llamado a que ese equilibrio no se quiebre y que cada parte cumpla con las reglas establecidas ${ }^{46}$.

El sistema penal acusatorio llena de herramientas a la defensa, que debe ser proactiva, ágil, preparada, propositiva, ya que cuando se habla del equipo de la defensa, no se trata solo del acusado-defensor, sino de técnicos en criminalística,

45 Manuel Fernando Moya, "Charla en la barra académica" (Bogotá: Escuela de la Defensoría del pueblo, 26 de agosto de 2016).

46 Antonio Luis González Navarro, La acusación en el sistema penal acusatorio (Bogotá: Leyer, 2013). 
investigadores, peritos y laboratorios dispuestos a fortalecer la teoría defensiva que se presentará ante el juez.

Por ello, la Defensoría del Pueblo constituyó el Grupo de Investigación Defensorial (GID), que dota a los defensores públicos de estos técnicos, profesionales, peritos y laboratorios, que abordan diferentes áreas de la criminalística y de la ciencia para cumplir con la misión de realizar una defensa técnica y material en favor de aquellos que no cuentan con los recursos económicos para asumir estos costos.

El GID, para el caso específico del departamento de Cundinamarca, cuenta con 2 profesionales especializados en criminalística, 3 profesionales especializados en investigación y 8 técnicos en criminalística, que cubren los 116 municipios, agrupados en 15 circuitos judiciales; es decir, en proporción, son 0,8 investigadores por circuito judicial, y por municipios equivaldría a una cantidad de 0,1 funcionarios para atender las solicitudes.

Aunque los números son desalentadores, la actividad que a la fecha se ha logrado ha sido importante para empezar a equilibrar el principio de igualdad de armas.

\section{Aplicación del principio de igualdad de armas por parte de los operadores, desde la perspectiva del defensor público de Cundinamarca}

Con el fin de obtener datos concretos respecto al desarrollo que ha tenido el principio de igualdad de armas, dentro de la Ley 906 de 2004, se realizó un trabajo de campo tomando como población de estudio a los defensores públicos que prestan su servicio en el departamento de Cundinamarca, ya que ellos son los profesionales que a diario atienden a las personas capturadas en situación de flagrancia o asumen la defensa cuando se solicita el servicio del Sistema Nacional de Defensoría Pública, cuando estas personas no tienen recursos económicos o cuando, por fuerza mayor, deban tener dicha representación ${ }^{47}$.

- Población: los defensores públicos pertenecientes al programa de la Ley 906/04, con los cuales se cubre el servicio en los 116 municipios de Cundinamarca.

47 Congreso, Ley 941 de 2005, art. 43. 
- Muestra: 49 de los 104 defensores públicos que prestan sus servicios en el departamento de Cundinamarca, pertenecientes al programa de la Ley 906/04.

- Metodología: estudio de campo.

- Instrumento: recolección de información por medio de encuestas.

- Alcance de la investigación: descriptivo.

Con el fin de establecer la percepción del desarrollo del principio de igualdad de armas, desde la perspectiva de los defensores públicos, se aplicó una encuesta con 12 preguntas, con opciones de respuesta predeterminadas, de las cuales se podían marcar una o varias. Así mismo, se obtuvieron comentarios y/o aportes durante la aplicación del instrumento; algunos de ellos se relacionan a continuación.

\subsection{Pregunta 1}

¿Cuánto tiempo lleva litigando en el sistema penal acusatorio (Ley 906 de 2004) como defensor público en el departamento de Cundinamarca?

Entre 1 y 2 años Entre 3 y 5 años

Entre 6 y 9 años Entre 10 y 12 años

Figura 1. Pregunta 1 de la encuesta

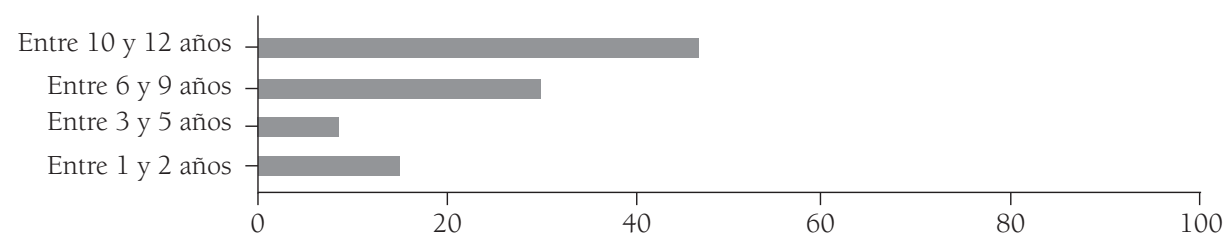

Fuente: elaboración propia.

El 46,8 \% de los encuestados llevan litigando entre 10 y 12 años en el sistema penal acusatorio, y el 29,7\%, entre 6 y 9 años, con lo cual se observa que más de la mitad de los encuestados cuentan con experiencia de más de 6 años en la Ley 906 de 2004. Las respuestas son fruto de su ejercicio profesional en desarrollo del contrato de prestación de servicios que tienen con la Defensoría del Pueblo, en el 
cual prestan turnos y atienden a los usuarios del Sistema Nacional de Defensoría Pública que llegan por asignación o por las diferentes audiencias. Los defensores asumen desde las audiencias preliminares, hasta las de juicio oral, ya que siguen con el caso hasta culminar con el proceso por sentencia o terminación anormal del proceso (preacuerdos y/o negociaciones).

\subsection{Pregunta 2}

En su experiencia como litigante en el sistema penal acusatorio (Ley 906 de 2004), ¿considera que el principio de igualdad de armas se materializa en el desarrollo de las audiencias?

Nunca Casi nunca Algunas veces Casi siempre

Figura 2. Pregunta 2 de la encuesta

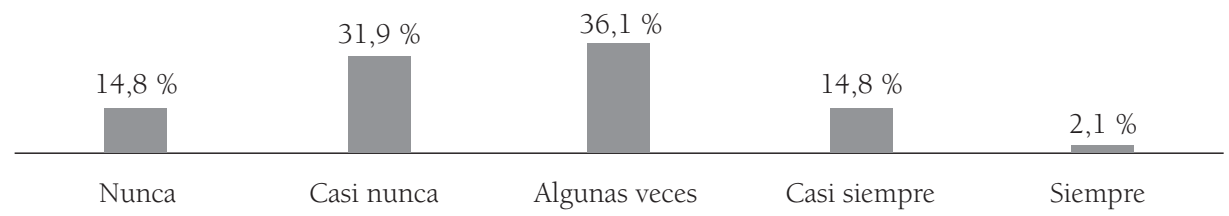

Fuente: elaboración propia.

El 36,1 \% de los defensores públicos considera que en las audiencias, algunas veces se materializa el principio de igualdad de armas; el 31,9\% dice que casi nunca; el 14,8\% considera que nunca; el 14,8\% cree que casi siempre, mientras que el $2,1 \%$ dice que siempre. Con lo anterior se evidencia que es mayor el número de defensores que no ven materializado el principio en las audiencias, situación que vulnera los derechos, ya que en ellas se pueden tomar decisiones trascendentales para el procesado.

\subsection{Pregunta 3}

En su experiencia como defensor público, indique en cuál o cuáles audiencias se vulnera el principio de igualdad de armas (puede marcar varias opciones).

Audiencias concentradas Audiencias reservadas Audiencia de acusación Audiencia preparatoria__ Audiencia de juicio oral__ 
Figura 3. Pregunta 3 de la encuesta

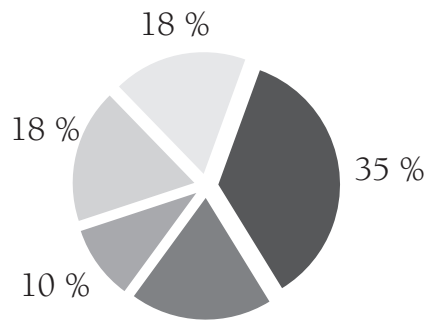

$19 \%$
- Audiencias concentradas

- Audiencias reservadas

- Audiencia de acusación

Audiencia preparatoria

Fuente: elaboración propia.

Teniendo en cuenta que el proceso penal dispone varias audiencias, se preguntó a los defensores públicos en cuál o cuáles de las opciones consideran que se vulnera el principio de igualdad de armas, eligiendo las audiencias concentradas con el $76,5 \%$; seguidas por las audiencias reservadas con un 40,4\%; señalaron también la audiencia preparatoria y la audiencia de juicio oral con un 38,2 \% cada una, y la audiencia de acusación, con el 21,2\%.

Durante la recolección de los datos, los defensores manifestaron que la audiencia de imputación, sea en audiencias concentradas o cuando el indiciado es llamado a escuchar la comunicación de la fiscalía, es en la que más se viola el principio no solo de igualdad de armas, sino de defensa, al no tener acceso al contenido de los elementos que el fiscal tiene en la carpeta; así, tomar decisiones tan importantes, como la de allanarse o no, se asumen sin conocer lo que posee la contraparte.

Respecto a las audiencias reservadas en etapa de indagación, no se tiene presencia de la defensa, motivo por el cual ejercer alguna clase de oposición no es posible y el juez toma decisiones de vulneración de derechos fundamentales únicamente con la exposición de motivos de la Fiscalía, lo cual es muestra de violación del derecho de igualdad de armas y de defensa.

Finalmente, los encuestados manifestaron que un momento importante del proceso es la audiencia preparatoria y el juicio oral, pero que la práctica de pruebas se dificulta para la defensa, porque generalmente se decreta la mayoría de pruebas y testigos solicitados por la FGN, y se restringe a la defensa. 


\subsection{Pregunta 4}

Desde su experiencia como defensor público, ¿considera que la Fiscalía General de la Nación cumple con la aplicación del principio de igualdad de armas?

Nunca Casi nunca Algunas veces Casi siempre

Figura 4. Pregunta 4 de la encuesta

\begin{tabular}{ccccc}
$23,4 \%$ & $23,4 \%$ & $40,4 \%$ & $10,6 \%$ & $2,1 \%$ \\
\hline Nunca & Casi nunca & Algunas veces & Casi siempre & Siempre
\end{tabular}

Fuente: elaboración propia.

Se observa que los encuestados consideran que la Fiscalía cumple algunas veces con el principio, en un 40,4 \% de las veces; casi siempre, 10,6 \%; nunca y casi nunca, $46,8 \%$, y solo el 2,1 \% considera que la Fiscalía siempre cumple con su deber de aplicar el principio de igualdad de armas. Esta situación vulnera los derechos, ya que la ley y la jurisprudencia ordenan a la FGN cumplir con su deber de descubrir lo favorable y lo desfavorable al acusado, situación que no siempre se presenta.

\subsection{Pregunta 5}

Desde su experiencia como litigante, ¿los jueces garantizan y exigen la aplicación del principio de igualdad de armas a las partes?

Nunca Casi nunca Algunas veces Casi siempre

Figura 5. Pregunta 5 de la encuesta

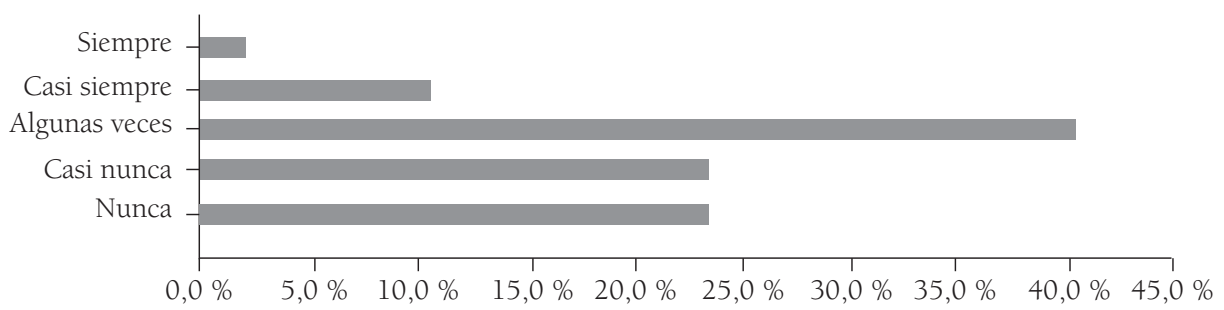

Fuente: elaboración propia. 
Esta pregunta busca establecer si los jueces, como garantes del proceso, realizan acciones para que el principio de igualdad se materialice, pero solo el 2,1 \% de los encuestados consideran que los jueces siempre propenden por el principio; el 10,6\% dice que casi siempre; el 40,4\%, algunas veces, un 23,4\% considera que los jueces nunca exigen su aplicación y otro 23,4 \% que casi nunca es así. Se considera que esta situación requiere especial atención, porque si las partes fallan o realizan actuaciones que ponen en desventaja a la contraparte, es el juez quien debe encausar el proceso y exigir la aplicación de los principios; pero si omiten su deber constitucional, el equilibrio se rompe en contra de alguna de las partes, generalmente la más débil, es decir, quien enfrenta la acusación.

\subsection{Pregunta 6}

¿De qué manera la Fiscalía General de la Nación vulnera el principio de igualdad de armas? (Puede marcar varias opciones)

Oculta resultados favorables al acusado Realiza descubrimientos parciales No permite el análisis de los EMP y EF que tiene en su poder__ Abulta los delitos, agravantes y/o calificantes, para lograr allanamientos_ Realiza un descubrimiento incompleto__ En la audiencia de acusación, indica que aún existen pruebas en producción

Figura 6. Pregunta 6 de la encuesta

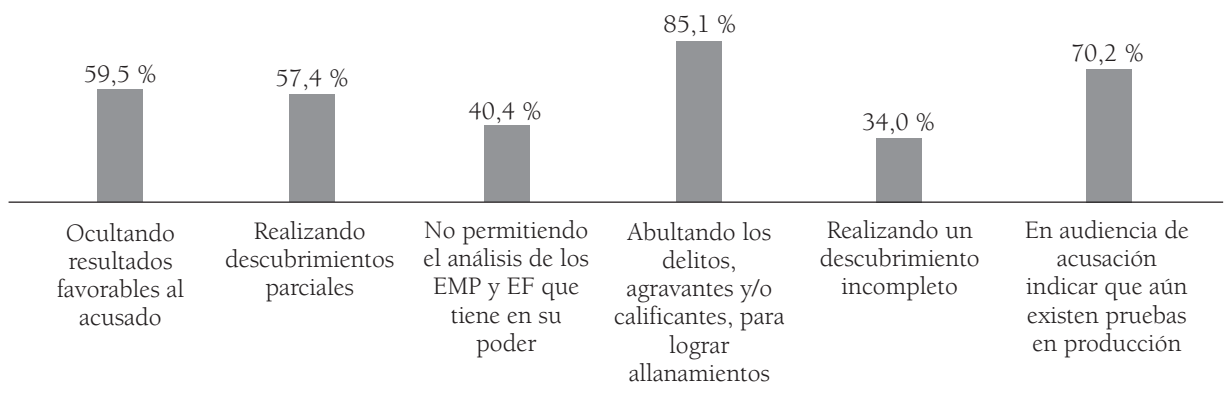

Fuente: elaboración propia.

Los defensores consideran que la práctica que más vulnera el principio de igualdad de armas por parte de la Fiscalía es la de abultar delitos, agravantes y/o calificantes, con un $85,1 \%$, con el fin de lograr que el procesado se allane a cargos en las primeras audiencias. Esta es una conducta habitual, según los encuestados, porque realizar 
acusaciones con penas altas genera que el procesado se allane si le reducen delitos, excluyen agravantes y/o calificantes, para así obtener una pena reducida; es una práctica que afecta no solo el principio de igualdad de armas, sino la presunción de inocencia, el debido proceso y de defensa.

Un 70,2 \% de los encuestados indica que en audiencia de acusación, la Fiscalía argumenta que aún existen pruebas en producción, lo cual vulnera el principio de igualdad, porque si el fiscal descubre elementos incompletos, la estrategia defensiva puede variar o fracasar cuando finalmente se entregan los resultados, pues se tendría un tiempo reducido para que la defensa recopile nueva información y/o elementos materiales de prueba, o para solicitar su análisis por parte de un perito que desvirtúe la tesis de la FGN.

El 59,9\% de los encuestados consideran que la práctica de ocultar resultados favorables al acusado es violatoria no solo del principio de igualdad de armas, sino del derecho de defensa y del debido proceso, por ser obligación legal entregar no solo lo desfavorable, sino lo favorable, para ser usado en el caso defensivo.

Seguido con el 57,4\% de encuestados que considera que realizar descubrimientos parciales deja a la defensa con algunos elementos, sin permitir que se realice un análisis completo e integral de estos, lo que también es una forma de afectar el principio de igualdad de armas.

No permitir el análisis de los elementos materiales de prueba (EMP) y evidencia física (EF) que tiene la Fiscalía, alega el 40,4\%, y realizar un descubrimiento incompleto, el $34 \%$, dejan a la defensa con elementos fraccionados o sin tiempo para recurrir a un perito que analice, explique y exponga el resultado de los elementos sometidos a la custodia de la FGN, lo cual viola la igualdad de medios.

\subsection{Pregunta 7}

¿Considera que los intervinientes (representante de víctimas, Ministerio Público) realizan acciones que vulneran el principio de igualdad de armas?

Nunca Casi nunca Algunas veces Casi siempre 
Figura 7. Pregunta 7 de la encuesta

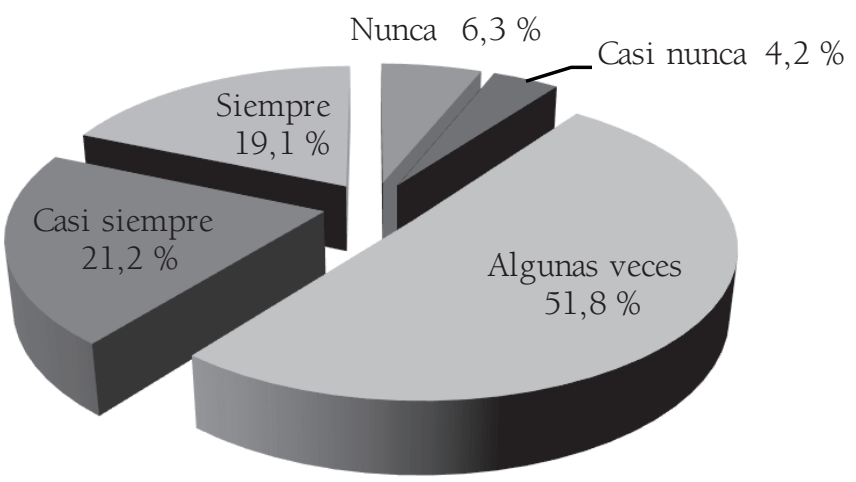

Fuente: elaboración propia.

Dentro del sistema adversario colombiano, además de las partes (Fiscalía-defensa), existen los intervinientes, como el representante de víctimas y la Procuraduría —en cuanto representante del Ministerio Público-, los cuales velan por el buen desarrollo del proceso.

Desafortunadamente, el 51,8 \% de los encuestados consideran que los intervinientes realizan acciones que vulneran el principio de igualdad de armas; el 21,2 \% afirma que casi siempre sucede dicha situación; el 19,1 \% dice que siempre; mientras que el 4,2 \% afirma que casi nunca sucede, y solo el 6,3\% afirma que nunca, lo que muestra un indicativo fuerte que muestra la injerencia de quienes no son parte en el equilibrio del proceso, que se constituye en un factor que vulnera el principio de igualdad de armas entre los que sí son parte del proceso.

\subsection{Pregunta 8}

¿En qué audiencia los intervinientes (representante de víctimas, Ministerio Público) realizan acciones que vulneran el principio de igualdad de armas?

Audiencias concentradas Audiencias reservadas Audiencia de acusación Audiencia preparatoria Audiencia de juicio oral 
Figura 8. Pregunta 8 de la encuesta

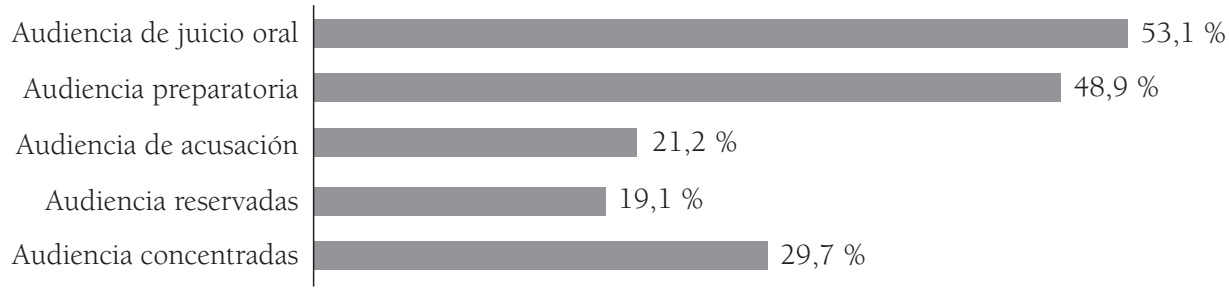

Fuente: elaboración propia.

En el sistema penal colombiano se exponen ante el juez dos posturas, generalmente opuestas, por parte de la Fiscalía y de la defensa; al existir otras opiniones a favor de alguna de estas, se quiebra el principio de igualdad de armas y el derecho de defensa. Por ello, se puede establecer que el 53,1 \% de los defensores encuestados consideran que los intervinientes realizan acciones que vulneran el principio en las audiencias de juicio oral, momento en el que se decidirá la responsabilidad del acusado; seguida por la audiencia preparatoria, con un 48,9\%, al exponer su posición respecto al decreto o no de algunas de las pruebas que se practicarán en el juicio oral; el 29,7\% considera que esto ocurre en las audiencias concentradas, al estar a favor o en contra de lo solicitado por las partes ante un juez de garantías; finalmente, el 21,2\% de los encuestados consideran que se vulnera el principio en la audiencia de acusación, y el 19,1 \%, en las audiencias reservadas.

\subsection{Pregunta 9}

¿Considera que la Defensoría del Pueblo está a la par, respecto a los medios humanos, técnicos, científicos y financieros de su contraparte, la Fiscalía General de la Nación?

Sí No

Figura 9. Pregunta 9 de la encuesta

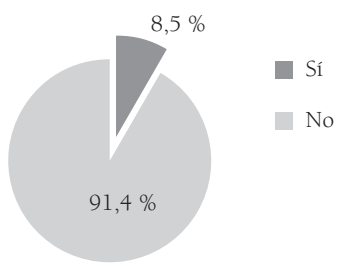

Fuente: elaboración propia. 
El 91,4 \% de los defensores consideran que la Defensoría no se encuentra en igualdad frente a los medios con los que cuenta la Fiscalía General de la Nación; mientras que el 8,6\% piensa que sí está en condiciones de equivalencia, teniendo en cuenta que la Fiscalía, al adelantar una investigación, debe garantizar el derecho de defensa, y cuando la persona acude al Sistema Nacional de Defensoría Pública, esta debe realizar su labor para garantizar todos los derechos del procesado y adelantar una investigación igual a la de su contraparte.

\subsection{Pregunta 10}

¿Cuáles de estas herramientas que brinda la Defensoría del Pueblo considera más útil para garantizar el derecho de igualdad de armas frente a la Fiscalía?

Barras académicas para exponer los casos

Investigadores y técnicos del Grupo de Investigación Defensorial

Peritos y laboratorios del Grupo de Investigación Defensorial

Figura 10. Pregunta 10 de la encuesta

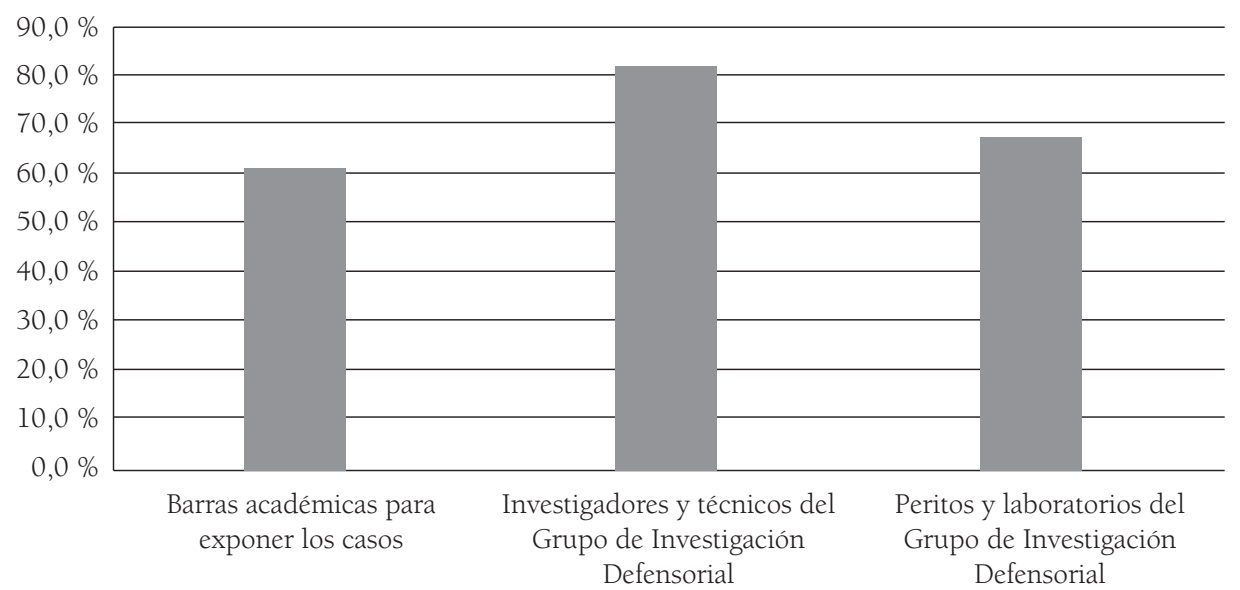

Fuente: elaboración propia.

El 82,9\% de los defensores consideran que la herramienta más útil para enfrentar un proceso penal es contar con los investigadores y técnicos del Grupo de Investigación Defensorial, ya que, al desplegar todas las actividades de investigación, se 
puede desvirtuar lo dicho por la acusación; se puede alcanzar la efectividad al lograr ubicar no solo testigos, sino elementos materiales de prueba y evidencia física para introducirlos al proceso, así como lo hace la Fiscalía con sus funcionarios de Policía Judicial. Los encuestados manifiestan en un 65,9 \% que los peritos y laboratorios del GID son importantes para enfrentar la FGN, porque los dictámenes periciales y elementos materiales de prueba y/o evidencia física deben ser analizados por el experto, y dar un punto de vista objetivo al juez en la audiencia correspondiente. Finalmente, las barras académicas, con un $61,7 \%$, son consideradas como efectivas, pues a partir de ellas se obtienen diferentes criterios, conceptos y posiciones jurídicas de expertos y colegas ante casos particulares, con los cuales podrían resolver situaciones complejas.

\subsection{Pregunta 11}

¿Cuál de estas herramientas usa usted como defensor público para enfrentar un caso presentado por la Fiscalía General de la Nación? (Puede marcar varias opciones)

Barras académicas para exponer los casos

Investigadores y técnicos del Grupo de Investigación Defensorial

Peritos y laboratorios del Grupo de Investigación Defensorial

Figura 11. Pregunta 11 de la encuesta

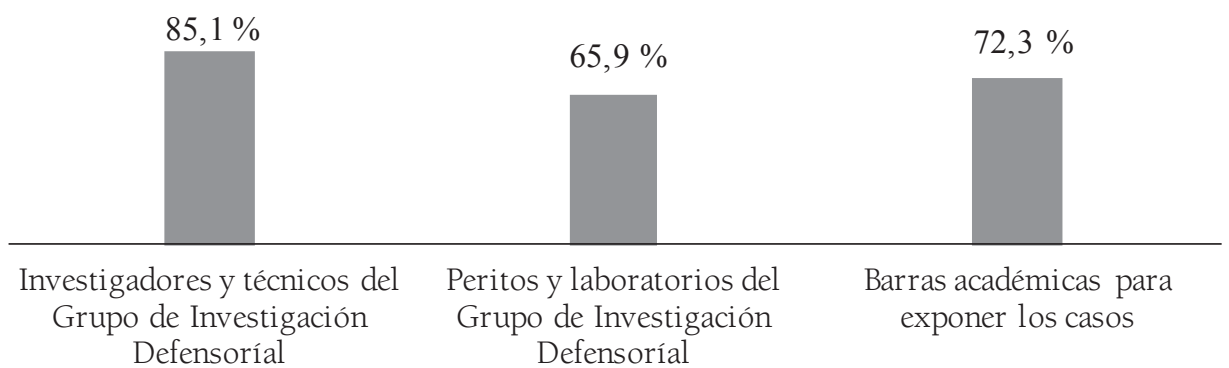

Fuente: elaboración propia.

Según los encuestados, el 85,1 \% utiliza el servicio de investigadores y técnicos del GID para estructurar su caso defensivo, para ello solicitan actividades de investigación; el 72,3 \% complementa los casos con la exposición de estos en barras 
académicas; así mismo, el 65,9 \% manifestó que acude a los peritos y laboratorios dispuestos por el GID.

\subsection{Pregunta 12}

Teniendo en cuenta la respuesta de la pregunta 11 , indique si usted ha obtenido respuesta favorable (si) o desfavorable (no) a sus inquietudes y/o solicitudes para fortalecer un caso como defensor público, en:

Barras académicas para exponer los casos

Investigadores y técnicos del Grupo de Investigación Defensorial

Peritos y laboratorios del Grupo de Investigación Defensorial

Figura 12. Pregunta 12 de la encuesta

Sí No

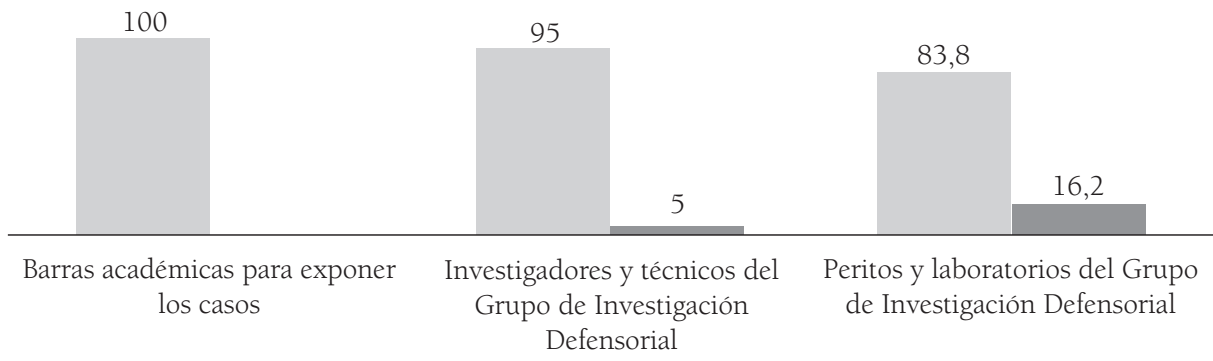

Fuente: elaboración propia.

De los defensores públicos que manifestaron haber usado las barras académicas para obtener una orientación, el $100 \%$ de ellos manifestaron que recibieron respuesta a sus inquietudes, bien sea del coordinador de la barra o de sus colegas. Respecto a los investigadores y técnicos del GID, los encuestados manifestaron que el $95 \%$ de las veces recibieron respuesta favorable a lo solicitado. Respecto a los peritos y laboratorios, el 83,8 \% de las solicitudes lograron una respuesta propicia para ser usada en la tesis de defensa. Con lo anterior se establece la importancia de tener un equipo que desarrolla actividades como lo hace la Fiscalía, desde el punto de vista de la investigación, pericial y profesional. 


\section{Conclusiones}

El principio de igualdad de armas supone formalmente que las partes tengan equivalencia de medios, recursos, investigadores, laboratorios, para que lleguen a las audiencias con las mismas posibilidades de persuadir al juez, quien imparcialmente toma una decisión con las pruebas ante él practicadas. Sin embargo, los defensores públicos de Cundinamarca consideran, en un 91,4\% (figura 9), que la defensa está en desigualdad frente a la FGN, lo que vulnera no solo el principio de igualdad de armas, sino el derecho de defensa.

Se demuestra que el principio de igualdad de armas no ha tenido un desarrollo significativo, a pesar de su importancia, según lo planteado en la hipótesis. Con la actividad de campo se establece que, desde la percepción de los defensores públicos del departamento de Cundinamarca, el principio ha sido afectado sensiblemente por diferentes factores, como el no acatamiento al deber de entregar todo el material por parte de la Fiscalía, o por acciones o "maniobras" que buscan el allanamiento del acusado - por ejemplo, al incluir en la tipificación más delitos, agravantes y/o calificantes de los que realmente podrían llegar a ser, lo que hace más gravosa la situación jurídica del procesado (figura 6)—.

Otro factor que transgrede el principio analizado es el hecho de no tener acceso al contenido de la carpeta del fiscal, como sucede en las audiencias concentradas (legalización de captura, imputación y medida de aseguramiento), en las cuales la persona debe tomar la decisión de allanarse o continuar enfrentando la acusación del Estado (figura 6); todo esto, frente a jueces que, según la información recopilada, el 46,8 \% de las veces nunca o casi nunca propenden por el equilibrio de las partes (figura 5), lo que quiebra derechos de rango constitucional, como el derecho a la defensa.

Una de las bases del sistema penal adversarial es la discusión Fiscalía-defensa frente al juez, pero en el trabajo de campo se encontró que los intervinientes, es decir, los representantes de las víctimas y del Ministerio Público, rompen el principio de igualdad el 92,1 \% de las veces, en el desarrollo de las audiencias (siempre, casi siempre y algunas veces [figura 7]), más aún cuando el 91,4 \% de los defensores públicos consideran que se está en desigualdad frente a todos los medios que tiene el ente acusador (figura 9). Por esta razón, se deben establecer límites a las injerencias de los intervinientes, que rompen el equilibrio de las partes y vulneran el derecho a la defensa. 
Con la recopilación y análisis de la información aportada por los defensores públicos de Cundinamarca, se puede afirmar que el principio de igualdad de armas en la actualidad no ha tenido el desarrollo e impacto que se pretendía, ya que se ordenaba a la FGN investigar para acusar, y la defensa precisaba hacer lo propio en igualdad de medios y oportunidades, pero falta mucho para lograr consolidar esta igualdad y obtener resultados más efectivos en la prestación de justicia en Cundinamarca.

Impacta saber que los jueces no ejerzan en forma debida su rol, y no garanticen y exijan a las partes sus obligaciones, porque son ellos quienes al final del proceso definirán la suerte del acusado. Finalmente, la injerencia que realizan los intervinientes afecta de manera importante no solo el principio de igualdad de armas, sino de defensa y debido proceso, sin encontrar límites claros para su ejercicio y tampoco la utilidad vital de su presencia en el proceso penal, lo cual sería tema para un posterior estudio a profundidad.

Los encuestados consideran muy importante enfrentar el proceso con los resultados que entregan los investigadores y técnicos del Grupo de Investigación Defensorial (GID); igualmente, el apoyo de los peritos y laboratorios cumple una labor sustancial (figura 10), lo cual muestra un avance evidente en la consolidación de una de las herramientas que brinda la Defensoría del Pueblo para materializar el principio de igualdad de armas. Aunque el número de investigadores, respecto a los investigadores del CTI y de la Sijin, podría ser insuficiente, se observa que cuando los defensores han solicitado los servicios del GID, el $95 \%$ de las veces han obtenido respuesta favorable (figura 12), lo cual fortalece la estrategia defensorial.

Se encontró que la incorporación de la imputación en el sistema de tendencia acusatoria que pretendía activar la defensa se convirtió en uno de los momentos que quiebran no solo la igualdad de armas, al no poder realizar ninguna clase de actuación por parte de la defensa por no tener acceso a la carpeta del fiscal, sino en una violación a derechos de rango constitucional, porque es en ese momento en que el presunto responsable de un hecho, sin conocer los elementos que posee la Fiscalía, debe tomar la decisión de allanarse o negociar frente a la imputación, que además es abultada el 85,1 \% de las veces (figura 6).

Finalmente, se encuentra que los términos para la investigación de la defensa frente a los de la Fiscalía son insuficientes, y de nada sirve una comunicación del ente acusador si no se tiene acceso a los fundamentos y elementos que soportan la imputación, con el fin de realizar en tiempo y oportunidad la recolección del 
material probatorio útil para ejercer la defensa y garantizar así la igualdad de armas de cara al proceso penal.

\section{Referencias}

Arias Duque, Carlos. La nacional de capacitación: sistema nacional de Defensoría Pública. Bogotá: Defensoría del Pueblo/USAID, 2006.

Barbosa Castillo, Gerardo. "Principio de legalidad y proceso penal". Revista Derecho Penal

y Criminología Universidad Externado de Colombia, vol. 26, n. 78 (2005): 109-123.

Bernal Castro, Carlos Andrés. (Coord.). Reflexiones de derecho penal y procesal penal. Bogotá:

Defensoría del Pueblo, 2013.

Chiappe Piraquive, Yolanda. El derecho de defensa frente a la formalización de la Investigación.

Reflexiones de derecho penal y procesal penal. Bogotá: Imprenta Nacional, 2013.

Congreso de Colombia, Cámara de representantes. "Informe de ponencia para primer debate al proyecto de Ley 01 de 2003" (24 de octubre de 2003). http://www.imprenta.gov. co/gacetap/gaceta. mostrar_documento?p_tipo=22\&p_numero=01\&p_consec $=7350$. Daza González, Alfonso. (2009) "El principio de igualdad de armas en el sistema procesal penal Colombiano a partir del Acto Legislativo 03 de 2002”. Revista Principia IURIS. Centro de investigaciones Socio-Jurídicas USTA TUNJA, 12 (2009). http://revistas.ustatunja.edu.co/index.php/piuris/article/view/396.

Daza González, Alfonso. (2010) El principio de igualdad de armas en el sistema procesal penal Colombiano. Bogotá D.C.: Grupo Editorial Ibáñez.

Defensoría del Pueblo. Manual del investigador desde la perspectiva de la defensa. Bogotá, 2008. Departamento Nacional de Estadística de Colombia. 2016. Demografía y población. Proyecciones de población. http://www.dane.gov.co/index.php/estadisticas-por-tema/ demografia-y-poblacion/proyecciones-de-poblacion.

Federal Judicial Center. El sistema judicial de los EEUU. (2007). http://www2.fjc.gov/sites/ default/files/2014/US_Legal_Sys_Spanish_2007_Jul.pdf.

Fernández León, Whanda. El mito de la igualdad de armas. Ámbito Jurídico. (2014). https://www.ambitojuridico.com/BancoConocimiento/Educacion-y-Cultura/ noti-143010-05-el-mito-de-la-igualdad-de-armas.

González Navarro, Antonio Luis. La acusación en el sistema penal acusatorio. Bogotá: Leyer, 2013.

Jiménez Montes, Fernando y Carlos Eduardo Valdés Moreno. Colección sistema penal acusatorio, Tomo I. Bogotá: Universidad Católica de Colombia, 2009.

Judicial Branch Home, Cortes de California. "Cómo funcionan los casos penales". (s. f.). http://www.courts.ca.gov/1069.htm. 
Moya Vargas, Manuel Fernando. Cuatro aspectos polémicos de la ley 906 de 2004. Bogotá: Imprenta Nacional de Colombia, 2006.

_. Charla en la barra académica. Bogotá: Escuela de la Defensoría del Pueblo, 26 de agosto de 2016.

Otero Mendoza, Iván Alfredo. "Ineficacia del ejercicio del derecho a la defensa técnica en el proceso penal a la luz del principio de igualdad de armas". En Temas de defensa penal, Tomo I. Bogotá: Imprenta Nacional de Colombia, 2014.

Reyes Medina, C. A. Técnicas del proceso oral en el sistema penal acusatorio colombiano: (2a ed.). Manual General para operadores jurídicos. Bogotá: USAID, 2009.

Sánchez, Alejandro. "Modelo procesal penal colombiano ies adversarial?" Ámbito Jurídico, n. ${ }^{\circ} \mathrm{xx}$ (2016). https://www.ambitojuridico.com/BancoConocimiento/Penal/modeloprocesal-penal-colombiano-es-adversarial? CodSeccion=1.

Sánchez Lugo, Carlos Felipe. El desarrollo de nuestro sistema penal de corte acusatorio y la actuación de las partes e intervinientes frente a disposiciones constitucionales. Análisis y aportes para su consolidación. Reflexiones de derecho penal y procesal penal. Bogotá: Imprenta Nacional, 2013.

Solórzano Garavito, Carlos Roberto. Sistema acusatorio y técnicas del juicio oral. $4^{\mathrm{a}}$ ed. Bogotá: Ediciones Nueva Jurídica, 2012.

Unites States of America Embasy. "Sistema judicial de E.U.: viejas tradiciones, nuevas direcciones". (Mayo de 2003). http://iipdigital.usembassy.gov/st/spanish/texttrans/2 003/06/20030617113215neerge0.9618189.html\#ixzz4M4UqOKg2

Uprimny Yepes, Rodrigo, Gerardo Barbosa Castillo, Alejandro Aponte Cardona, Óscar Julian Guerrero Peralta, Darío Bazzani Montoya y José Joaquín Urbano Martínez. Reflexiones sobre el nuevo sistema procesal penal. Los grandes desafíos del juez penal colombiano. Bogotá: Imprenta Nacional, 2006.

\section{Normatividad}

Constitución Política de Colombia. 1991. http://www.corteconstitucional.gov.co/inicio/ Constitucion\%20politica\%20de\%20Colombia\%20-\%202015.pdf.

Presidencia de la República. Decreto 2550 (30, diciembre, 2015), por el cual se liquida el Presupuesto General de la Nación para la vigencia fiscal de 2016, se detallan las apropiaciones y se clasifican y definen los gastos. http://inm.gov.co/images/Normatividad/Decretos/ Decreto_\%202550_2015.pdf.

Congreso de la República. Ley 600 (24 de julio de 2000), por la cual se expide el Código de Procedimiento Penal. Bogotá: Diario Oficial 44.097 del 24 de julio de 2000. 
Congreso de la República. Ley 906 (31 de agosto de 2004), por la cual se expide el Código de Procedimiento Penal. (Corregida de conformidad con el Decreto 2770 de 2004). Bogotá: Diario Oficial 45.658.

Congreso de la República. Ley 941 (14 de enero de 2005), por la cual se organiza el Sistema Nacional de Defensoría Pública. Bogotá: Diario Oficial 45.790 del 14 de enero de 2004.

\section{Jurisprudencia}

Corte Constitucional de Colombia, Sala de revisión 6. Sentencia No. T-432/92. Igualdad ante la ley/derechos fundamentales/igualdad formal/igualdad material Ref.: Proceso de tutela No. 860. MP Simón Rodríguez. Bogotá: 25 de junio de 1992.

Corte Constitucional de Colombia, Sala Plena. Sentencia SU 1300/01 Precedente ConstitucionalFuerza vinculante/Precedente Constitucional-Conceptos. Referencia: expediente T-463299. MP Marco Gerardo Monroy Cabra. Bogotá: 6 de diciembre 2001.

Corte Constitucional de Colombia, Sala Plena. Sentencia C-799/05, Cosa Juzgada ConstitucionalConfiguración. Obligaciones de los servidores judiciales y derecho a la igualdad-Protección de personas que se encuentren en circunstancias de debilidad manifiesta. Referencia: expediente D-5464. MP Jaime Araujo Rentería. Bogotá: 2 de agosto de 2005.

Corte Constitucional de Colombia. Sentencia T-1110/05. Acción de tutela contra sentenciasCausales de procedibilidad. Referencia: expediente T-1150497, MP Humberto Antonio Sierra Porto. Bogotá: 28 de octubre de 2005.

Corte Constitucional de Colombia, Sala Plena. Sentencia C-127/11. Omisión Legislativa Relativa-Concepto/Omisión Legislativa Absoluta-Concepto. Referencia: expediente D-8228. MP María Victoria Calle Correa. Bogotá: 2 de marzo de 2011.

Corte Suprema de Justicia, Sala de Casación Penal. Sentencia SP12031-2015, MP Luis Guillermo Salazar Otero. Bogotá: 9 de septiembre de 2015.

Corte Suprema de Justicia, Sala de Casación Penal. Sentencia AP5911-2015 Radicación No. 46109 (Aprobado Acta No. 356). MP Fernando Alberto Castro Caballero. Bogotá: 8 de octubre de 2015. 


\section{Anexo. Encuesta a defensores públicos \\ Universidad Católica de Colombia}

\section{Centro de Investigaciones Sociojurídicas (CISJUC)}

Encuesta para la obtención de información de los defensores públicos de la regional Cundinamarca, del programa Ley 906/04, dentro del trabajo "Principio de igualdad de armas en el Sistema Penal Acusatorio: realidad formal o violación al derecho fundamental de igualdad en Cundinamarca".

A continuación encontrará unas preguntas, las cuales se solicita conteste con base en su experiencia como defensor público. Dicha información será utilizada como insumo para establecer la percepción del desarrollo del principio de igualdad de armas en el marco de la Ley 906/04 ("Artículo 8. Defensa. En desarrollo de la actuación, una vez adquirida la condición de imputado, este tendrá derecho, en plena igualdad respecto del órgano de persecución penal [...]" [cursivas mías]), y su valoración será estadística, cualitativa-cuantitativa.

\section{Pregunta 1}

¿Cuánto tiempo lleva litigando en el sistema penal acusatorio (Ley 906 de 2004) como defensor público en el departamento de Cundinamarca?

Entre 1 y 2 años Entre 3 y 5 años

Entre 6 y 9 años Entre 10 y 12 años

\section{Pregunta 2}

En su experiencia como litigante en el sistema penal acusatorio (Ley 906 de 2004), ¿considera que el principio de igualdad de armas se materializa en el desarrollo de las audiencias?

Nunca Casi nunca Algunas veces Casi siempre 


\section{Pregunta 3}

En su experiencia como defensor público, indique en cuál o cuáles audiencias se vulnera el principio de igualdad de armas (puede marcar varias opciones).

Audiencias concentradas Audiencias reservadas Audiencia de acusación Audiencia preparatoria Audiencia de juicio oral

\section{Pregunta 4}

Desde su experiencia como defensor público, ¿considera que la Fiscalía General de la Nación cumple con la aplicación del principio de igualdad de armas?

Nunca Casi nunca Algunas veces Casi siempre

\section{Pregunta 5}

Desde su experiencia como litigante, ¿los jueces garantizan y exigen la aplicación del principio de igualdad de armas a las partes?

Nunca Casi nunca Algunas veces Casi siempre

\section{Pregunta 6}

¿De qué manera la Fiscalía General de la Nación vulnera el principio de igualdad de armas? (Puede marcar varias opciones)

Oculta resultados favorables al acusado Realiza descubrimientos parciales No permite el análisis de los EMP y EF que tiene en su poder__ Abulta los delitos, agravantes y/o calificantes, para lograr allanamientos_ Realiza un descubrimiento incompleto__ En la audiencia de acusación, indica que aún existen pruebas en producción

\section{Pregunta 7}

¿Considera que los intervinientes (representante de víctimas, Ministerio Público) realizan acciones que vulneran el principio de igualdad de armas? 
Nunca __ Casi nunca __ Algunas veces __ Casi siempre __

\section{Pregunta 8}

¿En qué audiencia los intervinientes (representante de víctimas, Ministerio Público) realizan acciones que vulneran el principio de igualdad de armas?

Audiencias concentradas__ Audiencias reservadas__ Audiencia de acusación _ Audiencia preparatoria_ Audiencia de juicio oral_

\section{Pregunta 9}

¿Considera que la Defensoría del Pueblo está a la par, respecto a los medios humanos, técnicos, científicos y financieros de su contraparte, la Fiscalía General de la Nación?

Sí No

\section{Pregunta 10}

¿Cuál de estas herramientas que brinda la Defensoría del Pueblo considera más útil para garantizar el derecho de igualdad de armas frente a la Fiscalía?

Barras académicas para exponer los casos

Investigadores y técnicos del Grupo de Investigación Defensorial

Peritos y laboratorios del Grupo de Investigación Defensorial

\section{Pregunta 11}

¿Cuál de estas herramientas usa usted como defensor público para enfrentar un caso presentado por la Fiscalía General de la Nación? (Puede marcar varias opciones)

Barras académicas para exponer los casos

Investigadores y técnicos del Grupo de Investigación Defensorial

Peritos y laboratorios del Grupo de Investigación Defensorial 


\section{Pregunta 12}

Teniendo en cuenta la respuesta de la pregunta 11 , indique si usted ha obtenido respuesta favorable (si) o desfavorable (no) a sus inquietudes y/o solicitudes para fortalecer un caso como defensor público, en:

Barras académicas para exponer los casos

Investigadores y técnicos del Grupo de Investigación Defensorial

Peritos y laboratorios del Grupo de Investigación Defensorial 